\title{
Airway calibre as a confounder in interpreting bronchial responsiveness in asthma
}

\author{
Asger Dirksen, Flemming Madsen, Thim Engel, Lars Frølund, John H Heinig, \\ Holger Mosbech
}

\begin{abstract}
Background The relation between airway responsiveness to constrictor agents and forced expiratory volume in one second $\left(F E V_{1}\right)$ is important when interpreting change in airway responsiveness after an intervention. The aim of the study was to analyse the relation between $\mathrm{FEV}_{1}$ as a percentage of predicted values (\% predicted) and airway responsiveness between and within asthmatic subjects.

Methods Results of non-specific bronchial challenge tests were pooled from two randomised crossover studies comparing the effect of a non-sedative antihistamine with placebo in 35 patients with moderate asthma. The design of the two studies was similar: the provocative concentration of either histamine (first study) or methacholine (second study) resulting in a $20 \%$ decrease in ventilatory capacity $\left(\mathbf{P C}_{20}\right)$ was repeated at two week intervals while patients were treated with the antihistamine or placebo. The dose of inhaled corticosteroid was gradually reduced during the study. Data were analysed with $\mathbf{P C}_{20}$ as the dependent variable in a general linear model so that the influence on $\mathbf{P C}_{20}$ of inhaled corticosteroid dose, antihistamine, and choice of bronchoconstricting agent could be separated from
\end{abstract} the influence of $F E V_{1} \%$ predicted.

Results The correlation coefficient between mean $\mathbf{P C}_{20}$ and mean prechallenge $\mathrm{FEV}_{1}$ for each patient was 0.45 . In the general linear model two thirds $(65 \%)$ of the variation in $\mathbf{P C}_{20}$ was due to variation between subjects. One third of the within subject variation in $\mathbf{P C}_{20}$ could be explained by variation in prechallenge $\mathrm{FEV}_{1} \%$ predicted (a change in $\mathrm{FEV}_{1}$ of $27 \%$ predicted was associated with one doubling or halving of $\left.\mathbf{P C}_{20}\right)$. Treatment with the antihistamine had no influence on $\mathbf{P C}_{20}$, except when histamine was used as the bronchoconstricting agent. The dose of inhaled corticosteroid had a small but significant effect.

Conclusions The variation in a patient's $\mathbf{P C}_{20}$ over time (several months) is related to changes in $F E V_{1} \%$ predicted. Variation in $\mathrm{FEV}_{1} \%$ predicted explains less of the variation in bronchial responsiveness between subjects where a patient specific factor, which is probably related to the pathogenesis of bronchial asthma, seems to dominate.

(Thorax 1992;47:702-706)
The relation between airway calibre and bronchial responsiveness is still controversial and important when results from bronchial challenge tests are evaluated. This applies to comparisons within and between patients.

Asthmatic subjects have been examined extensively because the influence of baseline airway calibre on bronchial reactivity will act as a confounder when the effect of an intervention such as occupational exposure, drug treatment, immunotherapy, or allergen avoidance on bronchial reactivity is examined.

In this study we analysed pooled data from two randomised clinical trials comparing the effect of a non-sedative antihistamine (loratadine) with placebo in 35 patients with moderate asthma. ${ }^{1}$ The patients had 12 histamine or methacholine bronchial challenge tests. We examined the relation between prechallenge forced expiratory volume in one second $\left(\mathrm{FEV}_{1}\right)$ and bronchial responsiveness (the provocative concentration of constricting agent resulting in a $20 \%$ decrease in $\mathrm{FEV}_{1}$ $\left(\mathrm{PC}_{20}\right)$ ), account being taken of the type of bronchoconstricting agent and the doses of antihistamine and inhaled steroid.

\section{Patient and methods}

PATIENTS

Fourteen men (19 to 56 years of age) and 21 women (19 to 62 years of age) (table 1) were included after they had shown (a) more than a $20 \%$ variation in peak expiratory flow (PEF) recorded during a two week period and $(b)$ at least a $15 \%$ improvement in $\mathrm{FEV}_{1} 10$ minutes after inhalation of $0.2 \mathrm{mg}$ salbutamol. They had their asthma well controlled while taking inhaled beclomethasone dipropionate $200 \mu \mathrm{g}$ twice daily, with a baseline $\mathrm{FEV}_{1}$ above $50 \%$ of the predicted normal value (Quanjer summary equation $s^{2}$ ). No patient had taken oral steroids for the previous two months or for longer than three months during the previous year. No patient had any other serious disease or was pregnant. All had a normal chest radiograph. Informed consent was obtained from all patients, and both studies were approved by the local ethical committee.

\section{DESIGN}

The two studies were set up primarily to investigate the effects of the antihistamine loratadine in patients with asthma. ${ }^{1}$ In this paper we took the opportunity provided by the large number of measurements of bronchial responsiveness to examine possible influences on bronchial responsiveness.

Both studies had a double blind, ran- 
Table 1 Characteristics of the 35 asthmatic patients studied

\begin{tabular}{lcr}
\hline Characteristic & Mean $^{\star}$ & Range $^{\star}$ \\
\hline Sex (No of men/women) & $14 / 21$ & \\
Age (years) & 40 & $19-62$ \\
Duration of asthma (years) & 17 & $2-31$ \\
Allergy: & & \\
$\quad$ Seasonal (\%) & 29 & \\
$\quad$ Perennial (\%) & 57 & \\
Smoking: & & \\
$\quad$ Never smoked (\%) & 68 & \\
Ex-smoker $(\%)$ & 26 & \\
$\quad$ Current smoker (\%) & 6 & $155-192$ \\
Height (cm) & 172 & $1.68-5.20$ \\
Baseline FEV FE $_{\text {Litres }}$ & 2.82 & $53.0-118.0$ \\
$\quad \%$ Predicted & 82.5 & $0.03-7.00$ \\
Baseline PC $_{20}$ (mg/ml) & 0.68 & \\
\hline
\end{tabular}

^Unless otherwise specified.

domised, placebo controlled, crossover design with two treatment periods (loratadine and placebo), each lasting 10 weeks. The washout period between the two treatment periods lasted for at least one month. The treatment periods started with a bronchial challenge test followed by a two week running in period to ensure that asthma was stable while patients took inhaled beclomethasone dipropionate $200 \mu \mathrm{g}$ twice daily. The bronchial challenge test was then repeated and the patients were randomly allocated to receive the antihistamine or placebo capsule. During the following eight weeks the inhaled steroid was gradually reduced by $50 \mu \mathrm{g}$ twice daily every second week-that is, at 4 weeks, 6 weeks, and 8 weeks-to a total dose of $50 \mu \mathrm{g}$ twice daily for the last two weeks. For emergency treatment the patients were supplied with a salbutamol inhaler $(0.1 \mathrm{mg} /$ puff $)$, which they were instructed to use when needed for immediate relief from exacerbations of their symptoms. Other antiasthmatic treatment remained constant throughout the study.

Patients kept daily records of asthma symptoms (scores for wheezing, dyspnoea, cough, sputum, and nocturnal asthma), PEF, and use of drug treatment throughout the treatment periods. At the end of every second week the patients were seen by one of the investigators, their diaries were checked, and spirometry and a measurement of non-specific bronchial responsiveness were performed. Thus bronchial challenge tests were performed 12 times for each patient.

The two studies differed in two respects. The dose of loratadine was $10 \mathrm{mg}$ daily in the first study and $20 \mathrm{mg}$ daily in the second. The bronchoconstricting agent was histamine in the first study and methacholine in the second.

FORCED EXPIRATORY VOLUME

Maximal $\mathrm{FEV}_{1}$ was measured with a dry wedge spirometer (Vitalograph, Buckingham, United Kingdom) as the largest value resulting from three technically correct maximal forced expiratory manoeuvres whose variation between the two best values was less than $5 \%$.

BRONCHIAL CHALLENGE

Bronchial challenge was performed by means of a non-cumulative dose-response protocol. ${ }^{3}$ After an initial saline inhalation the patients inhaled unbuffered histamine dihydrochloride in the first study and methacholine chloride in the second study in doubling doses from $0.015 \mathrm{mg} / \mathrm{ml}$ to $16 \mathrm{mg} / \mathrm{ml}$. The inhalations were performed for two minutes with intervals of five minutes between them. $\mathrm{FEV}_{1}$ was recorded at 30 and 90 seconds after inhalation, and the inhalation was interrupted when a decrease of at least $20 \%$ of the post-saline $\mathrm{FEV}_{1}$ was observed. At rechallenge the starting concentration of bronchoconstrictor was at least two steps below the previously observed $\mathrm{PC}_{20}$, or $0.015 \mathrm{mg} / \mathrm{ml}$.

The provocative concentration $\left(\mathrm{PC}_{20}\right)$ was calculated by linear interpolation between the last two points on the log dose-response curve. Interpolation between $\mathrm{FEV}_{1}$ saline and $\mathrm{FEV}_{1}$ threshold dose was never performed. The same Wright nebuliser was used throughout both studies. When driven by compressed air at 1.3 bar and a flow of $13 \mathrm{l} / \mathrm{min}$, the output was 150 (SD 10) $\mu \mathrm{l} / \mathrm{min}$ and the aerodynamic diameter for $99 \%$ of the dry particles was within $0.5-$ $1.5 \mu \mathrm{m}$.

Patients abstained from bronchodilator treatment before each challenge. ${ }^{3}$ Study treatment (loratadine or placebo) and inhaled corticosteroids were continued unchanged. In accordance with our standard protocol we confirmed that patients had not had an infection, had not smoked for four hours and had not been exposed to relevant allergens or occupational agents.

\section{STATISTICAL ANALYSIS}

The relation between prechallenge $\mathrm{FEV}_{1}$ and bronchial responsiveness $\left(\mathrm{PC}_{20}\right)$ was summarised for each patient by plotting the results of the 12 challenge tests in a line derived from the regression model:

$$
\log _{2}\left(\mathrm{PC}_{20}\right)=\mathrm{k}_{0}+\mathrm{k}_{1} \star \mathrm{FEV}_{1} \text {, }
$$

where the dependent variable $P_{20}$ was logarithmically transformed to base 2 . The purposes of the transformation were to stabilise variances, to linearise relations, to make distributions more normal, and to enable results to be presented in an acceptable scale of measurement.

The relation between $\mathrm{PC}_{20}$ and other variables was further examined by fitting a general linear model:

$$
\begin{aligned}
\log _{2}\left(\mathrm{PC}_{20}\right)= & \text { Ptno }+\mathrm{FEV}_{1}+ \\
& \text { Ptno } \mathrm{FEV}_{1}+\mathrm{BDP}+\mathrm{LHM},
\end{aligned}
$$

where Ptno is a patient specific factor (patient number) representing the variation in level of bronchial reactivity between asthmatics-that is, the interindividual variation in $\mathrm{PC}_{20} . \mathrm{FEV}_{1}$ is prechallenge $\mathrm{FEV}_{1}$ as a quantitative variable (\% predicted); Ptno ${ }^{*} \mathrm{FEV}_{1}$ is an interaction term between the patient specific factor and prechallenge $\mathrm{FEV}_{1}$ to test homogeneity of slopes (see figure 1). BDP is dosage of inhaled steroid as a quantitative covariate, and LHM is dose of antihistamine ( $\mathrm{L}=$ loratadine) combined with type of bronchoconstricting agent ( $\mathbf{H}=$ histamine and $\mathbf{M}=$ methacholine) as a qualitative factor with four categories: (a) no 
Figure 1 Relation between $P C_{20}$ and $F E V$ $\%$ predicted in 35 asthmatic patients for each patient expressed in a line model: $\log _{2}\left(P C_{20}\right)$ $=k_{0}+k_{1} \star F E V_{1} \%$ the interval from the minimal to the maximal prechallenge $F E V, \%$ predicted of the patient. derived from the regression predicted. The lines span
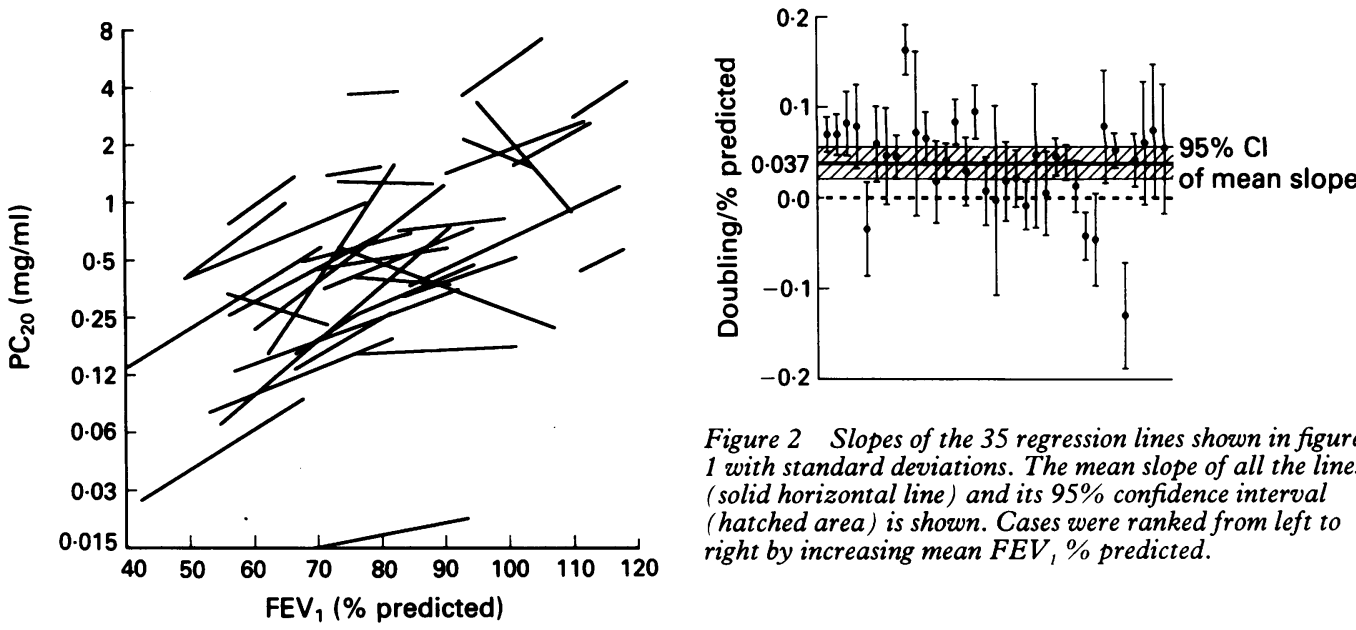

Figure 2 Slopes of the 35 regression lines shown in figure 1 with standard deviations. The mean slope of all the lines (solid horizontal line) and its $95 \%$ confidence interval (hatched area) is shown. Cases were ranked from left to right by increasing mean $F E V, \%$ predicted.

antihistamine in two weeks before bronchial challenge with histamine; $(b)$ no antihistamine in two weeks before bronchial challenge with methacholine; (c) loratadine $10 \mathrm{mg}$ daily in the two weeks before bronchial challenge with histamine; and (d) loratadine $20 \mathrm{mg}$ daily in two weeks before bronchial challenge with methacholine.

\section{Results}

The relation between bronchial responsiveness $\left(\mathrm{PC}_{20}\right)$ and $\mathrm{FEV}, \%$ predicted is shown in figure 1. Despite individual variations in the slope of the lines there was a general tendency for increasing $\mathrm{FEV}, \%$ predicted to be associated with increasing $\mathrm{PC}_{20}$. The slope of the regression line for each patient and the standard deviation of the slope, with the mean slope and its $95 \%$ confidence interval, are shown in figure 2 . The mean slope differed significantly from zero $(\mathrm{p}<0.001)$.

The correlation coefficient $(r)$ between mean $\mathrm{PC}_{20}$ and mean $\mathrm{FEV}_{1} \%$ predicted for each subject was $0.45(\mathrm{p}<0.001)$, showing that some $\left(\mathrm{r}^{2}=20 \%\right)$ of the between subject variation in bronchial reactivity could be explained by between subject variation in prechallenge $\mathrm{FEV}_{1} \%$ predicted.

The results of the more comprehensive analysis of the variation in bronchial responsiveness $\left(\mathbf{P C}_{20}\right)$ in a general linear model are summarised in table 2 . Almost two thirds

Table 2 Analysis of variation in bronchial responsiveness $\left(P C_{20}\right.$ as dependent variable) in general linear model with various explanatory (independent) variables

\begin{tabular}{lllr}
\hline & $\begin{array}{l}\text { Mean }(S D) \\
\text { coefficient }\end{array}$ & $\begin{array}{l}\text { \% of } \\
\text { variation } \\
\text { explained }\end{array}$ & $\begin{array}{l}\text { F statistic } \\
\text { p value }\end{array}$ \\
\hline Source of variation & & & \\
Main effects: & - & 65 & 0.076 \\
$\quad$ Patient specific factor (patient number) & $0.037(0.010)$ & 11 & $<0.001$ \\
FEV (\% predicted) & $0.865(0.415)$ & 0 & 0.038 \\
Inhaled steroid (mg/day) & - & 3 & 0.091 \\
Two way interactions: & - & 5 & $<0.001$ \\
FEV patient specific factor & & 84 & \\
$\quad$ Antihistamine bronchoconstrictor & 16 & \\
Explained by model & & & \\
Residual variation & & & \\
\hline
\end{tabular}

$\mathrm{FEV}_{1}=$ prechallenge $\mathrm{FEV}_{1}(\%$ predicted $)$

*Combined dose of antihistamine (loratadine $0 \mathrm{mg}, 10 \mathrm{mg}$, or $20 \mathrm{mg}$ ) with choice of histamine or methacholine for the bronchial challenge (for further details see text).
$(65 \%)$ of the variation in $\mathrm{PC}_{20}$ could be ascribed to a patient specific factor-that is, between subject variation in level of hyperresponsiveness. One third $(35 \%)$ of the total variation in $\mathrm{PC}_{20}$ remained for within patient variation in responsiveness, and one third of this intraindividual variation $(11 \%$ of the total variation in bronchial reactivity) could be ascribed to within subject variation in prechallenge $\mathrm{FEV}$ $\%$ predicted $(p<0.001)$. The coefficient of prechallenge $\mathrm{FEV}_{1} \%$ predicted in the general linear model was 0.037 doublings $/ \%$ predicted $\mathrm{FEV}_{1}$, indicating that an increase in $\mathrm{FEV}_{1}$ by $27 \%$ of predicted values was associated with a doubling of $\mathrm{PC}_{20}$

The interaction term between prechallenge FEV $1 \%$ predicted and the patient specific factor did not reach significance $(p=0.09)$, which means that the variation in slope of individual patients in figures 1 and 2 can be explained by residual variation-that is, the low reproducibility of $\mathrm{PC}_{20}$ and $\mathrm{FEV}$ measurements. This means that the mean slope of the regression lines in figure 1 should be considered in predicting $P_{20}$ and that individual variation in the slope of the regression lines is less important. covariate $(\mathrm{p}<0.05)$, although less than $1 \%$ of the total variation in $\mathrm{PC}_{20}$ was explained by this variable. The interaction term including dose of antihistamine and type of bronchoconstricting agent was highly significant $(p<0.001)$, accounting for $5 \%$ of the variation in bronchial hyperresponsiveness. This factor had four categories and further analysis showed that the combination of loratadine $10 \mathrm{mg}$ daily with histamine as the challenge drug differed from the three other categories and that the differences between the three other categories were insignificant, or they had no influence on $\mathrm{PC}_{20}$.

\section{Discussion}

It has been recognised since the 1960 s that people with poorer lung function tend to have greater degrees of non-specific airway responsiveness. ${ }^{45}$ This relation has now been well documented in population samples ${ }^{6}$ and among cigarette smokers with chronic airflow obstruction and chronic mucus hypersecretion, ${ }^{78}$ but conflicting data have been reported on the
Inhaled steroid dosage was a significant 
correlation between lung function and degree of airway responsiveness among asthmatic subjects. In a study by Yan et al of 17 subjects with asthma identified on the basis of a doctor's diagnosis or intermittent wheezing or dyspnoea there was no significant correlation between lung function before challenge and $\mathrm{PD}_{20} \mathrm{FEV}_{1} \cdot{ }^{9}$ Rubenfeld and Pain observed no significant correlation between methacholine airway responsiveness and prechallenge specific airway conductance among 11 asthmatic volunteers with a wide range of prechallenge conductance, ${ }^{10}$ and Chung et al concluded that bronchial hyperreactivity in asthmatic subjects is unlikely to be a direct consequence of a low starting airway calibre. ${ }^{11} 12$ In contrast, Cockcroft et al observed a significant direct correlation between prechallenge $\mathrm{FEV}_{1}$ and $\mathrm{PC}_{20}$ $\mathrm{FEV}_{1}(\mathrm{r}=0.49)$ among 156 patients with well controlled atopic asthma, ${ }^{13}$ and a smaller study of 15 asthmatic subjects gave a similar correlation of $0.42 .{ }^{14}$ In our study we found a correlation coefficient of 0.45 .

In most studies bronchial reactivity has been measured on only a single occasion in each patient, and consequently investigators could analyse only between subject variation in bronchial responsiveness and ventilatory capacity. In a more recent longitudinal study of 20 asthmatic subjects reactivity to methacholine was measured every two to three weeks for 12 to 18 months. ${ }^{15}$ The aim of this study and therefore the statistical analyses differed from that of our study, however. The subjects' overall reactivity (median $\mathrm{PD}_{20}$ ) was related only to average variation in PEF, and the temporal relation between trends in $\mathrm{PD}_{20}$ and PEF and $F V_{1}$ within subjects was based on subjective interpretation of charted serial data in individual patients. The statistical analysis of the data was confined to Spearman's $\rho$, which did not take into account the possibility that treatment may have modified the degree of reactivity.

In our study non-specific airway responsiveness was measured 12 times in each patient at intervals of two (or more) weeks, which enabled us to analyse the within patient relation between prechallenge $\mathrm{FEV}_{1} \%$ predicted and bronchial reactivity $\left(\mathrm{PC}_{20}\right)$. The analysis was performed in a general linear model in which the influence of an inhaled corticosteroid, an antihistamine, and a choice of bronchoconstricting agent on bronchial hyperresponsiveness could be separated from the influence of $\mathrm{FEV}_{1} \%$ predicted.

Histamine and methacholine produce bronchoconstriction by different mechanisms, and a person's sensitivity to these different agents may vary. None the less, among asthmatic subjects a high correlation has been observed between methacholine and histamine responsiveness. ${ }^{16}$ In our general linear model splitting the LHM term into separate categories for bronchial challenge with histamine and challenge with methacholine did not improve the explanatory power of the model, and thus pooling of data from two studies differing with regard to bronchoconstricting agent was considered to be acceptable. Only a modest part of the variation in bronchial hyperresponsiveness could be explained by the effect of drugs (loratadine and inhaled corticosteroids). ${ }^{17} 18$

Two thirds $(65 \%)$ of the total variation in bronchial responsiveness could be ascribed to between subject variation, leaving one third of the variation to be explained by within subject variation. Only $16 \%$ of the total variation in non-specific airway responsiveness was not accounted for by the explanatory variables of the model.

The analysis showed that prechallenge $\mathrm{FEV}_{1}$ $\%$ predicted was a strong explanatory variable for between subject and especially within subject variation in bronchial responsiveness. The close within subject relation between prechallenge level of pulmonary function and degree of responsiveness to the bronchoconstricting agents may be explained in part at least by geometric factors. ${ }^{1920}$ Because the resistance of a tube is inversely related to its radius to the fourth power, a given degree of circumferential shortening of bronchial smooth muscle will cause a greater increase in airway resistance in a narrower airway than in a wider airway.

In addition to bronchoconstriction, asthma involves several mechanisms that may influence airway responsiveness. Chronic airway inflammation may alter the local production of lipid derived inflammatory mediators, impair local neuroregulation, and damage respiratory epithelium, possibly interfering with production of a putative epithelial derived relaxation factor. ${ }^{8}$ These mechanisms, which are probably part of the pathogenesis of bronchial asthma, may increase airway reactivity without concomitant narrowing of the airway and would explain why most of the between subject variation in bronchial responsiveness was not related to $\mathrm{FEV}_{1} \%$ predicted.

The results of an analysis of the relation between bronchial responsiveness to nonspecific bronchoconstrictors and airway calibre will depend on the selection of subjects for the study. All our patients had asthma with documented reversible airway obstruction and most were atopic and had not smoked cigarettes. Any admixture of normal subjects or patients who smoke and have chronic obstructive lung disease would be likely to strengthen the relation between airway responsiveness and $\mathrm{FEV}_{1}{ }^{8}$.

In conclusion, we found a large variation in bronchial responsiveness to histamine or methacholine between asthmatic subjects that was only moderately related to prechallenge $\mathrm{FEV}_{1} \%$ predicted. Variation in $\mathrm{FEV}_{1} \%$ predicted explained one third of the variation in the response of an individual patient, however, when bronchial challenge was repeated. The effect of an inhaled corticosteroid was small, and treatment with an antihistamine was important only when histamine was used as the bronchoconstricting agent.

The practical clinical aspect of our findings is that airway responsiveness cannot be predicted with any precision from an asthmatic patient's $\mathrm{FEV}_{1} \%$ predicted. Once bronchial reactivity has been determined, however, subsequent 
monitoring of bronchial responsiveness partly mirrors changes in $\mathrm{FEV}_{1}$, which can be monitored easily.

We thank Aksel Bertelsen from the Statistical Research Unit of the University of Copenhagen for statistical advice and for performing the general linear modelling in SAS (statistical performing the
analysis system).

1 Dirksen A, Engel T, Frølund L, Heinig JH, Svendsen UG, Weeke $B$. The effect of a non-sedative antihistaminic (loratadine) in moderate asthma. A double-blind controlled clinical crossover-trial. Allergy 1989;44:566-71.

2 Quanjer $\mathrm{PhH}$, ed. Standardized lung function testing. Report of the Working Party on Standardization of Lung Function Tests, European Community for Coal and Steel. Full Eur Physiopathol Respir 1983;19(suppl 5):1-95.

3 Cockroft DW, Killan DM, Kellon JJA, Hargreave FE. Bronchial reactivity to Inhaled Histamine. A method and clinical survey. Clin Allergy 1977;7:235-43.

4 Parker CD, Bilbo RE, Reed CR. Methacholine aerosol as test for bronchial asthma. Arch Intern Med 1965;115:452-8.

5 Simonsson BG. Clinical and physiological studies on chronic bronchitis. Acta Allergol 1965;20:325-48.

6 Rijcken B, Schouten JP, Weiss ST, Speizer FE, Van der Lende $R$. The relationship between airway responsiveness to histamine and pulmonary function level in a random population sample. Am Rev Respir Dis 1988;137:826-32.

7 Engel T, Heinig JH, Madsen O, Hansen M, Weeke ER. A comparison of airway responsivenss in smokers with chronic bronchitis and in asthmatic subjects. Eur Respir $J$ 1989;2:929-34.

8 O'Connor GT, Sparrow D, Weiss ST. The role of allergy and nonspecific airway hyperresponsiveness in the pathogenesis of chronic obstructive pulmonary disease. $\mathrm{Am} \mathrm{Rev}$ Respir Dis 1989;140:225-52.
9 Yan K, Salome CM, Woolcock AJ. Prevalence and nature of bronchial hyperresponsiveness in subjects with chronic obstructive pulmonary disease. Am Rev Respir Dis 1985; 132:25-9.

10 Rubenfeld AR, Pain CF. Relationship between bronchial reactivity, airway caliber, and severity of asthma. Am Rev Respir Dis 1977;115:381-7.

11 Chung KF, Morgan B, Keyes SJ, Snashall PD. Histamine dose-response in normal and asthmatic subjects. $\mathrm{Am} \mathrm{Rev}$ Respir Dis 1982;126:849-54.

12 Chung KF, Snashall PD. Effect of prior bronchoconstriction on the airway response to histamine in normal subjects. Thorax 1984;39:40-5.

13 Cockcroft DW, Killian DN, Mellon JJA, Hargreave FE. Bronchial reactivity to inhaled histamine: a method and clinical survey. Clin Allergy 1977;7:235-43.

14 Beaupre A, Malo JL. Histamine dose-response curves in asthma: relevance of the distinction between $\mathrm{PC}_{20}$ and asthma: relevance of the distinction between $\mathrm{PC}_{20}$ and 36:731-6.

15 Josephs LK, Gregg I, Mullee MA, Holgate ST. Nonspecific bronchial reactivity and its relationship to the clinical expression of asthma. Am Rev Respir Dis 1989;140:350-7.

16 Juniper EF, Frith PA, Hargreave FE. Airway responsiveness to histamine and methacholine: relationship to minimum treatment to control symptoms of asthma. minimum treatment to

17 Juniper EF, Frith PA, Hargreave FE. Long-term stability of bronchial responsiveness to histamine. Thorax 1982; 37:288-91.

18 Bel EH, Timmers MC, Zwinderman AH, Dijkman JH, Sterk PJ. The effect of inhaled corticosteroids on the maximal degree of airway narrowing to methacholine in asthmatic subjects. Am Rev Respir Dis 1991;143:109-13.

19 Benson MK. Bronchial hyperreactivity. Br J Dis Chest 1975; 69:227-39.

20 Tattersfield AE. Measurement of bronchial reactivity: a question of interpretation. Thorax 1981;36:561-5. 